\title{
Milicias y fronteras en la formación del Estado argentino. La regulación de la Guardia Nacional de Buenos Aires (1852-1880) ${ }^{1}$
}

\author{
Luciano Literas ${ }^{2}$ \\ CONICET-UBA
}

\begin{abstract}
Resumen
El artículo analiza la normativa de la Guardia Nacional entre 1852 y 1880, con el propósito de explorar la complejidad de su desarrollo de acuerdo a las disputas facciosas entorno al proyecto nacional y el avance de la frontera sobre los territorios indígenas en el contexto de organización y consolidación del Estado argentino. Sin el poder suficiente para monopolizar el poder coercitivo, el gobierno nacional debió depender de la capacidad de convocatoria militar de los gobiernos locales. Así se instauró y adquirió relevancia la Guardia Nacional formada por campesinos y vecinos domiciliados obligados a realizar ejercicios militares de forma regular y listos para acudir a todo llamado, so pena de cumplir servicio en el Ejército de Línea. Esto se sitúa en la dinámica general de progresiva dominancia del Estado como forma de integración socio política, mediante la apropiación de ámbitos funcionales en los diversos planos de la interacción social y que hacia finales del período de estudio implicó la sustitución del marco institucional provincial como principal eje articulador de relaciones sociales y la subordinación de la Guardia Nacional al Estado nacional. Los principales documentos utilizados fueron las leyes y decretos en materia militar elaborados entre 1852 y 1880 , los diarios de sesiones del Congreso nacional entre 1862 y 1874 y las memorias del ministerio de Guerra y Marina entre 1868 y 1881.
\end{abstract}

Palabras clave: Guardia Nacional - Estado - Fronteras

1 El siguiente trabajo pertenece a los proyectos "Políticas indígenas y estatales en los espacios de frontera del extremo sur americano: Chaco, Pampa, Patagonia y Banda Oriental (siglos XVIII y XIX)", financiado por la Agencia Nacional de Promoción Científica y Tecnológica de Argentina (PICT Bicentenario Tipo I, A, cod. 1430) y "De la sociedad de frontera a la consolidación nacional: actores sociales e identidades en la frontera sur argentina (siglo XIX)", financiado por la Universidad de Buenos Aires (UBACyT cod. 20020090200443). Ambos dirigidos por la Dra. Ingrid De Jong, a quien agradezco sus comentarios.

2 Investigador del CONICET, Sección Etnohistoria del Instituto de Ciencias Antropológicas de la Facultad de Filosofía y Letras, Universidad de Buenos Aires.

LITERAS, Luciano, "Milicias y fronteras en la formación del Estado argentino. La regulación de la Guardia Nacional de Buenos Aires (1852-1880)", en Avances del Cesor, Año IX, N 9, 2012, pp. 9-32. 


\begin{abstract}
The article discusses the National Guards rules between 1852 and 1880, in order to explore the complexity of their evolution, according to factional conflicts about the national political project and the ocuppation of indigenous territories. Without the capacity to monopolize coercive power, the national government depended on the local goverments military deployments. Thus the National Guard was established with peasants forced to do military exercises and ready to go to every call, under the penality of being sent to the border army. This happened during the gradual supremacy of the national state in social and political integration and that meant for one hand the replacement of the local frameworks as the hub of social relations and for other hand the National Guard subordination. The main documents used were the military laws and decrees between 1852 and 1880, the diaries of the national Congress sessions between 1862 and 1874, and the reports of the War and Marine department between 1868 and 1881 .
\end{abstract}

Key words: National Guard - State - Borders

\title{
1. Introducción
}

La caída del régimen rosista en 1852 implicó el conflictivo surgimiento de un nuevo orden político fundado en la legitimación y centralidad del Estado nacional y la conformación de una economía capitalista basada en la exportación de materias primas y alimentos. ${ }^{3}$ Uno de los factores que colaboró en este proceso fue la creciente sofisticación del aparato militar, implementándose mecanismos para obligar a la población a participar en calidad de miliciano, en el avance y la defensa de los territorios de frontera de acuerdo al esfuerzo del Estado por garantizar su incorporación y uso productivo. ${ }^{4}$ Sin embargo, para entonces el Estado-nación como entidad política era aún un proyecto y su construcción requirió un diseño institucional que articulara las formas sociales provinciales relativamente autónomas y preexistentes. ${ }^{5}$ Uno de los ejes polémicos de este proceso fue la configuración y centrali-

3 BALÁN, Jorge, "Una cuestión regional en la Argentina: burguesías provinciales y el mercado nacional en el desarrollo agroexportador", en Desarrollo Económico. Revista de Ciencias Sociales, 1978, 18 (69) pp 49-87. SÁBATO, Hilda, Capitalismo y ganadería en Buenos Aires: la fiebre lanar. 1850-1890, Editorial Sudamericana, Buenos Aires, 1989; HALPERIN DONGUI, Tulio, La formación de la clase terrateniente bonaerense, Prometeo Libros, Buenos Aires, 2007.

4 SÁBATO, Hilda, Capitalismo y ganadería..., Op. Cit. GARAVAGLIA, Juan Carlos, Construir el Estado, inventar la Nación. El Río de la Plata, siglos XVIII-XIX, Prometeo Libros, Buenos Aires, 2007. HORA, Roy, Los estancieros contra el Estado. La Liga Agraria y la formación del ruralismo político en la Argentina, Siglo XXI, Buenos Aires, 2009.

5 BRAGONI, Beatriz y MÍGUEZ, Eduardo, "De la periferia al centro: la formación de un sistema político nacional, 1852-1880", en BRAGONI, Beatriz y MÍGUEZ, Eduardo (coordinadores) Un nuevo orden político: provincias y Estado nacional, 1852-1880, Biblos, Buenos Aires, 2010, pp. 9-28. 
zación de una fuerza pública ${ }^{6}$ en un contexto donde coexistían y competían diversos actores con vocación de controlarla, ya que tanto el Estado como las provincias se encontraban en proceso de construcción y organización de sus respectivas arquitecturas institucionales. A su vez, existían aún en el territorio argentino vastas extensiones de territorios bajo dominio de diversas agrupaciones indígenas, existiendo así espacios de frontera caracterizados por la escasa presencia de estructuras estatales, la fuerte militarización social y su significatividad como base de movilización política. ${ }^{7}$ Estos espacios fueron de especial importancia en el despliegue del nuevo orden político, que implicaba la imposición de la supremacía militar del poder central sobre las formas precedentes de organización social (milicias locales y Estados provinciales).

El sistema de defensa estuvo constituido por dos fuerzas diferentes: el Ejército de Línea (en adelante EL) y la Guardia Nacional (GN). La primera de carácter regular y adscripta al poder central, la segunda organizada en cada provincia y movilizada según convocatorias eventuales, formada por vecinos domiciliados so pena de cumplir servicio en el EL. ${ }^{8}$ Sin la capacidad para monopolizar el poder coercitivo el gobierno nacional debió depender de la convocatoria militar de los gobiernos provinciales, por tanto requirió de la mediación de los gobernadores para afirmar su voluntad. En consecuencia, dicho poder no fue independiente de la injerencia de liderazgos sociales y territoriales con capacidad de infligir lealtades políticas a su favor (del que dependían, por ejemplo, la proposición de jefes de la GN) ${ }^{9}$ y el nuevo sistema político tuvo que disponer de prácticas e instituciones creadas primero en la dimensión local de poder.

La construcción estatal implicó subordinar la organización y movilización de la GN a

6 MACÍAS, Flavia, "Las fuerzas militares entre la provincia y la nación (1868-1874)", en Dossier: La milicias en acción, Historiapolítica.com, 2011, Disponible en : http://historiapolitica.com/dossiers/ dossiermilicias/.

7 MÍGUEZ, Eduardo, "La frontera sur de Buenos Aires y la consolidación del Estado liberal, 18521880", en BRAGONI, Beatriz y MÍGUEZ, Eduardo (coordinadores), Un nuevo orden político..., Op. Cit, pp. 79-97.

8 GARAVAGLIA, Juan Carlos, "De Caseros a la guerra del Paraguay: el disciplinamiento de la población campesina en el Buenos Aires postrosista (1852-1865)", en Illes i Imperis, Barcelona, 2001, No 5, pp. 53-80. GARAVAGLIA, Juan Carlos, Construir el Estado..., Op. Cit. MACÍAS, Flavia Julieta, “Ciudadanía armada, identidad nacional y Estado provincial. Tucumán, 1854-1870", en SÁBATO, Hilda y LETTIERI, Alberto (compiladores) La vida política en la Argentina del siglo XIX. Armas, votos y voces, Fondo de Cultura Económica, Buenos Aires, 2003, pp. 137-151.

9 MORONI, Marisa y ESPINOSA, José Manuel, "El reclutamiento para la Guardia Nacional en la Pampa central argentina, 1884-1902”, en CHUST, Manuel y MARCHENA, Juan (editores) Las armas de la nación. Independencia y ciudadanía en Hispanoamerica, Iberoamericana-Vervuert, Madrid-Frankfurt, 2007, pp. 247-262; BRAGONI, Beatriz y MÍGUEZ, Eduardo (coordinadores) Un nuevo orden político..., Op. Cit. 
pesar de que difícilmente los sectores políticos dirigentes eludían su movilización como forma de intervención pública, al ser canal de transmisión del régimen representativo estructurado por el concepto de ciudadano armado. ${ }^{10}$ La progresiva dominancia del Estado como forma de integración socio política (mediante la apropiación de ámbitos funcionales en los diversos planos de la interacción social) implicó hacia 1880 la sustitución del marco institucional provincial como principal eje articulador de relaciones sociales ${ }^{11}$ al tiempo que se avanzaba con éxito sobre los últimos territorios indígenas aún no sujetos. Un proceso de institucionalización del poder estatal que modificó la lucha segmental y competitiva de la sociedad republicana para dar lugar a un Estado unificado como forma dominante de integración. ${ }^{12}$

El siguiente trabajo aborda la construcción jurídico-institucional de la GN entre 1852 y 1880 y las particularidades del caso de la provincia de Buenos Aires. Los objetivos son observar cómo se operacionalizó jurídicamente el funcionamiento de la GN y evaluar la incidencia que tuvo en su regulación normativa el servicio de frontera con los territorios indígenas. Todo esto en el contexto mencionado de competencia política y jurisdiccional entre el Estado central y las provincias, y la retracción de la frontera tras el derrocamiento de Juan Manuel de Rosas y el irregular ritmo que asumió el avance sobre los territorios indígenas de Pampa y Patagonia a causa de los medios alternativos y simultáneos de relacionamiento que empleó el Estado. ${ }^{13}$ La particularidad del caso porteño radica en que fue allí donde se instituyó por primera vez la GN tras disolver las milicias del período rosista y donde existió una destacada coacción y militarización social por su situación fronteriza, los requerimientos de la guerra civil y su posición hegemónica en el despliegue del nuevo orden político.

Los principales documentos utilizados fueron el compendio de leyes y decretos en materia militar publicado en 1898 por Ercilio Domínguez ${ }^{14}$, los diarios de sesiones del Congreso Nacional recogidos por el Instituto de Historia del Parlamento Argentino, y las memorias del

10 SÁBATO, Hilda, "Milicias, ciudadanía y revolución: el ocaso de una tradición política (Argentina, 1880)", en BRAGONI, Beatriz y MÍGUEZ, Eduardo (coordinadores) Un nuevo orden político..., Op. Cit, pp. 227-244.

11 OSZLAK, Oscar, La formación del Estado argentino, Planeta, Buenos Aires, 1999.

12 DE JONG, Ingrid, "Las alianzas políticas indígenas en el período de organización nacional: una visión desde la política de Tratados de Paz (Argentina 1852-1880)", en QUIJADA, Mónica (editora) De los cacicazgos a la ciudadanía. Sistemas Políticos en la Frontera, Ibero-Amerikanisches Institut Preussischer Kulturbesitz, Berlín, 2011, pp. 81-146.

13 Ibídem.

14 DOMINGUEZ, Ercilio, Colección de leyes y decretos militares concernientes al Ejército y Armada de la República Argentina. 1810 á 1896, Compañía Sud-Americana de Billetes de Banco, Buenos Aires, 1898, T. II. 
ministerio de Guerra y Marina. A su vez, desde hace unos años diversos investigadores se han dedicado a explorar las características sociopolíticas de la GN. Creo conveniente mencionar el de Rinaldo Poggi ${ }^{15}$, centrado en la legislación de Buenos Aires entre 1862 y 1872, que ofrece además la perspectiva de sus gobernadores sobre el polémico servicio de fronteras. También a Juan Carlos Garavaglia ${ }^{16}$ que aunque en mayor parte dedicado a las milicias de primera mitad de siglo junto a Jorge Gelman ${ }^{17}$, abordó la aparición de la GN después de Caseros, situándose en los modos coercitivos y punitivos de reclutamiento heredados del rosismo. Por su parte Hilda Sábato ${ }^{18}$ vinculó la GN con la noción republicana de ciudadano en armas y su relación con las formas de participación política, abriendo un interesante campo de indagación. Beatriz Bragoni ${ }^{19}$ en la provincia de Mendoza y Flavia Macías ${ }^{20}$ en Tucumán, investigaron la organización y movilización de la GN en el contexto de disputas y alianzas políticas locales. Ambos abordajes tienen la virtud de poner en evidencia el modo en que las milicias eran producto del orden anterior a 1852, que el poder coactivo central y provincial no era independiente de liderazgos sociales y territoriales, y que en definitiva la configuración de la fuerza pública en el marco de la conformación del Estado nacional implicó terminar con la tradición miliciana provincial y subordinar a la GN al poder central. A estos hay que sumar los trabajos de Alberto Lettieri ${ }^{21}$ sobre el surgimiento de la GN y

15 POGGI, Rinaldo, Los gobernadores de Buenos Aires y la Guardia Nacional. 1862-1874, Fundación Nuestra Historia, Buenos Aires, 2000.

16 GARAVAGLIA, Juan Carlos, Construir el Estado..., Op. Cit. ; GARAVAGLIA, Juan Carlos, "De Caseros a la guerra del Paraguay...", Op. Cit.; GARAVAGLIA, Juan Carlos, "Ejército y milicia: los campesinos bonaerenses y el peso de las exigencias militares, 1810-1860", en Anuario IEHS, Tandil, 2003, No 18, pp. 153-187.

17 GELMAN, Jorge, "El fracaso de los sistemas coactivos de trabajo rural en Buenos Aires bajo el rosismo, algunas explicaciones preliminares”, en Revista de Indias, Madrid, 1999, V. LIX, No 215, pp. 123-141.

18 SÁBATO, Hilda, "Milicias, ciudadanía y revolución...", Op. Cit.; SÁBATO, Hilda, "Soberanía popular, ciudadanía y nación en Hispanoamérica: la experiencia republicana del siglo XIX". Almanack braziliense, 2009, No 9, pp. 23-40. http://www.almanack.usp.br/. SÁBATO, Hilda, "Resistir la imposición: revolución, ciudadanía y república en la Argentina de 1880”, en Revista de Indias, 2009, V. LXIX, No 246, pp. 159-182.

19 BRAGONI, Beatriz y MÍGUEZ, Eduardo (coordinadores) Un nuevo orden político..., Op. Cit.

20 MACÍAS, Flavia, “Ciudadanía armada...”, Op. Cit.; MACÍAS, Flavia, “Las fuerzas militares...”, Op. Cit.; MACÍAS, Flavia, "Política, Guardia Nacional y ciudadanos en armas. Tucumán, 1862-1868”, Entrepasados, 2010, en prensa.

21 LETTIERI, Alberto, "La guerra de las representaciones: la revolución de septiembre de 1852 y el imaginario social porteño", en SÁBATO, Hilda y LETTIERI, Alberto (compiladores) La vida política... Op. Cit., pp 97-114. 
las formas de identificación social porteña durante los primeros años post-rosistas ${ }^{22}, \mathrm{y}$ de Lorena Barbuto y Guido Cordero ${ }^{23}$ sobre la participación política de la GN bonaerense en el levantamiento mitrista de 1874 . Todos ellos tienen el mérito de comenzar a iluminar las características sociales, políticas y económicas de la GN; empresa en la que aún resta mucho por hacer y que este trabajo tiene el humilde propósito de enriquecer, analizando cómo se operacionalizó normativamente el funcionamiento de la GN y el impacto de la situación fronteriza en su regulación jurídica.

\section{De Caseros a Pavón: el nacimiento de la Guardia Nacional (1852-1862)}

A un mes de derrocado Juan Manuel de Rosas, el 8 de marzo de 1852 el Gobierno Provisional de Buenos Aires a cargo de Vicente López y Planes resolvió el establecimiento de la GN sin determinar régimen ni normas que la regulasen, aunque precisando que su objetivo era la custodia de las leyes y el apoyo a la autoridad constituida. Pocos días después se disolvieron las milicias de la ciudad y la campaña ${ }^{24}$ obligando al enrolamiento en la GN de sus miembros y de los ciudadanos incluidos según la ley vigente de $1823^{25}$, en un contexto de crónica escasez de hombres para el $\mathrm{EL}^{26}$. Esta ley pionera fue el primer instrumento específico para la regulación de las milicias en Buenos Aires. Distinguió entre la milicia activa de "mozos solteros con arraigo en el país, y por su falta en los casados, y de éstos, en los que tengan menos hijos", para "suplir la insuficiencia del ejército permanente para la defensa y seguridad del territorio"; y la pasiva, de hombres "de 45 a 60 años", convocada "cuando peligre la seguridad del Estado por invasión o rebelión". La GN heredó de las milicias de primera mitad de siglo su carácter cívico y universal (aunque siempre masculino),

22 En esta línea también mencionar EUJANIÁN, Alejandro, “¡Ciudadanos de todas las clases! A las armas. La Guardia Nacional en el proceso de formación de una identidad local”, en Dossier: $L a$ milicias en acción, Historiapolítica.com, 2011, Disponible en: http://historiapolitica.com/dossiers/ dossiermilicias/.

23 BARBUTO, Lorena y CORDERO, Guido, "Guardias Nacionales y revolución: la participación de las milicias en el levantamiento mitrista de 1874", Comunicación, I Taller de Jóvenes Investigadores en Problemáticas Regionales, Sociales e Históricas, IV Jornadas de la División de Historia, Universidad Nacional de Luján, 30 y 31 de agosto de 2011

24 Decreto, Buenos Aires, 17 de marzo, 1852.

25 Ley, Buenos Aires 17 de diciembre, 1823.

26 El 1 de marzo Valentín Alsina, ministro de López, solicitó urgentemente a los jueces de paz facilitar desertores, "vagos" y "malentretenidos" a las fuerzas militar. E1 30 de abril ordenó que una comisión de tres vecinos, presidida por el juez, clasifique a los "vagos, dañosos, sin hogar". Ver: GARAVAGLIA, Juan Carlos, "De Caseros a la guerra del Paraguay...”, Op. Cit., p. 65; GARAVAGLIA, Juan Carlos, "Ejército y milicia...”, Op. Cit., p. 175. 
la movilización en defensa de las leyes vigentes y las instituciones consideradas legítimas, el auxilio en las fronteras apoyando al EL, la exoneración del servicio según ocupación laboral y la temporalidad del servicio. La GN alude a la noción de ciudadanía en armas en tanto ejercicio de un derecho y un deber de defensa de las instituciones republicanas y sus leyes, que antepuso el vínculo de los ciudadanos con la constitución por encima del eventual gobierno ${ }^{27} \mathrm{Su}$ organización se llevó adelante en el ámbito provincial, y los conflictos inter e intraprovinciales fueron el terreno en el cual las elites políticas la convocaron en legítima defensa de las noveles instituciones y los pactos políticos. En el caso de Buenos Aires, en estos primeros años post-rosistas la GN ocupó un lugar central en los conflictos con la Confederación y del mismo modo, en la construcción de la identidad porteña al encarnar la ciudadanía armada en defensa de su territorio e instalar comportamientos, emblemas, virtudes y aspiraciones comunes. ${ }^{28}$

Tras la revuelta porteña del 11 de septiembre de 1852 la provincia porteña se separó de la Confederación y el general Bartolomé Mitre fue designado jefe de la GN. Las primeras normas dictadas fijaron el papel de la GN de Buenos Aires castigando el no enrolamiento con el servicio en el EL, pero al mismo tiempo refuncionalizándola como auxilio del EL en la frontera. ${ }^{29}$ Esto no era novedoso: cuando la milicias sustituyeron a las tropas veteranas que combatían a los realistas, el coronel Juan Ramón Balcarce (al mando miliciano desde 1814) procedió a su reorganización reforzando la obligación de prestar servicio en las fronteras y proponiendo que aquellos que no lo hicieran fueran incorporados a un cuerpo de línea, ${ }^{30}$ Cuando se oficializó el primer llamado a enrolamiento en noviembre de 1852, fue Mitre el único autorizado a dar excepciones ${ }^{31}$ y el gobierno porteño podía destinar al EL a los que no se enrolasen en la GN. Permitió además poner personero para la sustitución en el servicio, a cambio de que la persona se inscriba inmediatamente en la GN. ${ }^{32}$ Esta primera clave normativa de su funcionamiento penalizó la evasión de una obligación considerada cons-

27 SÁBATO, Hilda, 2009; SÁBATO, Hilda, "Milicias, ciudadanía y revolución...", Op. Cit., ; MACÍAS, Flavia, "Política, Guardia Nacional...", Op. Cit.

28 LETTIERI, Alberto, "La guerra de las representaciones...”, Op. Cit.

29 Al poco tiempo la Confederación adoptó instrumentos punitivos similares de acuerdo a las dificultades para concretar con éxito el enrolamiento de la GN durante 1854: tras la convocatoria los no enrolado o "sin papeleta correspondiente" serían destinados "á servir por el término de tres años en las filas del Ejército permanente". Decreto, Paraná, 28 de abril de 1854. Decreto, Paraná, 20 de junio de1855.

30 BIEDMA, José, Crónicas militares. Antecedentes históricos sobre la campaña contra el indio, Editorial Universitaria de Buenos Aires, Buenos Aires, 1975[1924], pp. 235-263.

31 COMANDO EN JEFE DEL EJÉRCITO, Reseña histórica y orgánica del Ejército argentino, Círculo Militar, Buenos Aires, 1971, T. I, p. 507.

32 Ley, Buenos Aires, 24 de noviembre, 1852. 
titutiva del estatus ciudadano, siendo un recurso idóneo para resolver la recurrente escasez de hombres en el EL y garantizar un modo de evitar el servicio a quienes pudieran solventar un personero. Es preciso mencionar además que la inscripción en el registro cívico (y en consecuencia la capacidad para ejercer el sufragio) dependió del enrolamiento en la GN.

Tras la creación de la GN en Buenos Aires, la Confederación autorizó al Congreso a reunir las milicias provinciales en defensa de sus leyes, contener insurrecciones y repeler invasiones, dejando en poder de cada provincia la creación de los cuerpos de GN y el nombramiento de sus jefes y oficiales. ${ }^{33}$ El modelo de organización de la Confederación será el que seguirán las provincias a lo largo de la década de 1850 para organizar su GN. Para supervisar esto se instauró la Inspección General, precisando por primera vez algo ya estipulado en Buenos Aires, que la GN sería destinada guarnecer las fronteras "contra la reiteradas incursiones de bárbaros". ${ }^{34}$ Incluso, en Buenos Aires cuando fracasó el sitio de la ciudad por las tropas de la Confederación en julio de 1853, el gobierno premió a los GN licenciándolos del servicio por un año y disolvió los regimientos exceptuando únicamente a los que operasen "sobre la Frontera del Estado". ${ }^{35}$ Esta excepcionalidad advierte la importancia de la situación fronteriza en los primeros años post-rosistas y el papel que ocuparán las milicias a lo largo de la formación y consolidación del Estado.

Aún así, la regulación normativa del servicio de GN en Buenos Aires y en la Confederación variará en virtud de los conflictos recíprocos coyunturales. Se observa que los sectores políticos dirigentes eventualmente desatendieron la defensa de la frontera con los territorios indígenas de Pampa y Patagonia cada vez que los enfrentamientos por la unificación estatal parecieron insoslayables. Así sucedió en las batallas de Cepeda (1859) y Pavón (1861) cuando una vez más la escasez de hombres para el servicio de armas y la agudización de las exigencias militares, reforzó mecanismos punitivos, recortó excepciones y modificó temporalmente la organización de la GN transfiriéndola de la órbita legislativa al Poder Ejecutivo (en adelante PE) omitiendo la capacidad de la cámara de representantes para movilizar contingentes, presente en las normativas desde los primeros años de la independencia. ${ }^{36}$

El conflicto entre Buenos Aires y la Confederación no impidió que sus representantes

33 Constitución de la Confederación Argentina, capítulo 4, artículo 24 en MINISTERIO DEL INTERIOR. PODER EJECUTIVO NACIONAL, Documentos de la conformación institucional argentina. 1782-1972, 1974. Decreto, Paraná, 28 de abril, 1854.

34 Decreto, Paraná, 5 de junio, 1854.

35 Decreto, Buenos Aires, 4 de enero, 1855; Decreto, Buenos Aires, 24 de enero, 1855. A pesar de que las papeletas de enrolamiento continuaron teniendo el mismo valor práctico.

36 Ley, Buenos Aires, 30 de octubre, 1858. Decreto, Paraná, 2 de julio, 1861; Documentos de la conformación institucional argentina. 1782-1972, Op. Cit.; SCOBIE, James, La lucha por la consolidación de la nacionalidad argentina. 1852-1862, Hachette, Buenos Aires, 1964, pp. 336-341. 
tomaran similares caminos para resolver la falta de ejércitos permanentes y procurar la defensa de las fronteras, al articular el EL y la GN en un solo sistema; aunque es preciso tener en cuenta que en el caso de la Confederación la adhesión provincial al pacto constitutivo no derivó en la aplicación inmediata y unívoca de las regulaciones pautadas en Paraná. La Confederación situó uno bajo autoridad del gobierno nacional, otro en gran medida de los gobernadores provinciales; generando la primera ambigüedad del poder coercitivo estatal. ${ }^{37}$ En el caso de Buenos Aires se penalizó el no enrolamiento en la GN con la participación del EL, el primero bajo órbita de las autoridades locales de la campaña y la segunda del gobierno central en Buenos Aires. Esta coexistencia del EL y la GN, supuso la puesta en escena de dos concepciones diferentes de organización y control de la fuerza pública, y del papel del Estado central y las provincias en su uso legítimo. ${ }^{38}$ Como se verá más adelante, esta ambigüedad trascendió la temporal separación de Buenos Aires del resto de las provincias. Será reeditada una vez reunificada la república tras la batalla de Pavón, ya que a la carencia de un ejército permanente y la falta de hombres para el EL se sumó la simultaneidad de conflictos provinciales y de la frontera con los territorios indígenas, que obligó a recurrir a la GN y constató su condición de fuerza pública descentralizada: esto es la articulación de una tradición político militar previa que legitimaba la capacidad de los gobernadores provinciales de organizarla, y la existencia de un poder central en construcción, con la prerrogativa teórica de movilizarla. ${ }^{39}$ Los intersticios normativos en torno a su organización y movilización ${ }^{40}$ (y que perdurarán hasta finales del período) implicaron que su control dependiera de la articulación de uno y otro ámbito institucional. La ambigüedad del poder coercitivo, así como el auxilio de la GN en la frontera, serán motivo de extensos debates en los sectores políticos dirigentes y su resolución se dará en la medida en que lleven con éxito la unificación política estatal y la disolución de las fronteras con los territorios indígenas.

En relación al funcionamiento de la GN, Buenos Aires procuró su reglamentación en 1857, modificada casi treinta años después. ${ }^{41}$ Se dictaminó el enrolamiento o renovación de la papeleta en veinte días en el batallón correspondiente al domicilio del individuo, la necesidad de solicitar licencia en caso de ausencia y se nombraron los jefes de la GN y comisarios de policía de cada partido responsables de verificar el cumplimiento de lo ordenado. Una vez finalizado el plazo, éstos estaban a autorizados a enviar emisarios militares a los domicilios para aprehenderlos y destinarlos al EL. Más allá de modificaciones parciales en relación a las licencias, esto se aplicó durante todo el período en Buenos Aires y después de 1862 en el resto del país. Además, se reglamentó por primera vez el servicio en la GN en virtud

37 SÁBATO, Hilda, "Milicias, ciudadanía y revolución...”, Op. Cit., p. 235.

38 SÁBATO, Hilda, "Resistir la imposición...", Op. Cit., p. 168.

39 MACÍAS, Flavia, "Política, Guardia Nacional...”, Op. Cit., p. 7-8.

40 Ídem, p. 19.

41 Decreto, Buenos Aires, 22 de junio, 1857. 
de los trabajos en la campaña, al estipular la forma en que debían exceptuarse de la GN a capataces y mayordomos de estancia ${ }^{42}$, de acuerdo a un problema recurrente: "los abusos introducidos relativamente á excepciones del servicio militar [...] siendo frecuente pretextar para obtenerlas, el hallarse desempeñando en los establecimientos de campo, las funciones de mayordomos ó capataces". Se advirtió que dichos títulos eran arrogados por "hombres que sin dirigir trabajos, ni tener peones á sus órdenes, á excepción de uno ó dos, se hallan al cargo aun de pequeños puestos", y que para ser excluidos el capital de las haciendas a su cargo debía superar los cuatro mil pesos metálicos. Para hacer efectiva la excepción se debía obtener un certificado del juez de paz asociado "á dos vecinos de respeto que él nombre", indicando su función dentro del establecimiento y la constatación del capital. Este certificado era entregado al jefe del regimiento para que conste la excepción en la papeleta de enrolamiento. Los oficiales del regimiento supervisarían la duración de la excepción ya que "no es permanente por su naturaleza" porque si el individuo cesaba sus obligaciones como capataz o mayordomo debía prestar servicio en la GN.

La consideración del papel del individuo en la estructura económica de la campaña para su enrolamiento, fue recurrente en el caso porteño y se observa también en un acuerdo celebrado por el departamento de Guerra, disponiendo que cada comandante en jefe de la frontera estableciera el número de GN requeridos para prestar servicio, argumentando que los relevos no se hacían con efectividad y que los contingentes "van incompletos". ${ }^{43}$ Lo distintivo es que se ordenó que los comandantes al dirigirse a los regimientos, tengan presente los partidos que fueran predominantemente ganaderos o agricultores, con el propósito de conciliar las exigencias del servicio con las tareas y ocupaciones productivas de los mismos GN. El trabajo fue una cuestión relevante desde los primeros años de la GN bonaerense, reflejando la preocupación por minorar su impacto en la economía de la campaña al considerar tanto el papel ocupacional de la persona como los ciclos productivos de la actividad agrícola y ganadera. Quizás como resultado de la presión de sectores terratenientes preocupados por las crecientes demandas militares del Estado en ciernes en un contexto de escasez de mano de obra, aunque esto ya es materia de futuros estudios.

La batalla de Pavón marcó un punto de inflexión y los cambios suscitados en la GN se enmarcaron a partir de entonces en el proceso de unificación política del Estado, bajo la hegemonía porteña. Finalizada la coexistencia conflictiva entre Buenos Aires y la Confederación, se procuró afianzar un principio de autoridad estable entre las provincias unificándolas bajo el liderazgo porteño. Este nuevo orden político debía traducirse en una integración política que requería la subordinación de poderes en competencia. ${ }^{44}$ Mitre, en calidad de Gobernador de Buenos Aires Encargado del Poder Ejecutivo Nacional, impulsó el “carácter

42 Decreto, Buenos Aires, 13 de agosto, 1858.

43 Acuerdo, Buenos Aires, 21 de diciembre, 1858.

44 BRAGONI, Beatriz y MÍGUEZ, Eduardo (coordinadores), Un nuevo orden político..., Op. Cit. 
federal" de la GN bonaerense situando bajo un solo mando las fuerzas de Buenos Aires y de la Confederación ${ }^{45}$, dispuso la recepción y los honores dedicados a la GN victoriosa en Pavón ${ }^{46}$, "nacionalizó" el ministerio porteño de Guerra a cargo del general Juan Gelly y $\mathrm{Obes}^{47}$, creó la Inspección General de Milicias Provinciales desligándose formalmente Mitre de la GN bonaerense ${ }^{48}$ e indultó a los GN que permanecían fuera del país a causa de los recientes conflictos. ${ }^{49}$

Sin embargo, al nacionalizar el ministerio de Guerra porteño se señaló que no correspondía a las provincias la administración militar, con excepción de la organización de la GN sobre la que debería ejercer jurisdicción inmediata. Desde entonces y hasta las vísperas de la revuelta provocada por la federalización de Buenos Aires, se procuró homogeneizar en términos estatales la normativa de la GN a pesar de que se conservó la ambigüedad del sistema de defensa heredado de la década de 1850. El poder central en construcción se articuló con la tradición político militar rosista en un marco de ambigüedad normativa sobre su organización y movilización..$^{50}$ Mientras tanto, la GN ocupó un lugar central en los conflictos internos y externos vinculados a la organización y consolidación del Estado, como fueron la guerra con Paraguay, el avance de la frontera y el sofocamiento de las rebeliones en las provincias. Una vez resuelto el conflicto entre la Confederación y Buenos Aires, estos últimos serán los frentes que deberá atender sucesiva y simultáneamente el Estado en proceso en consolidación ${ }^{51}$ y que situarán a la GN como uno de los ejes del escenario político.

\section{El papel de la Guardia Nacional en la frontera con el indio (1863-1872)}

En los primeros años de unificación política del Estado, los problemas derivados de la defensa y avance de las fronteras con los territorios indígenas más los conflictos facciosos del proceso en ciernes (como las resistencias de las provincias a los intentos hegemónicos porteños) y la guerra del Paraguay, agudizaron las carencias de efectivos para el ejercicio de la coacción, hecho que fue la base para que el discurso normativo reforzara el carácter auxiliar necesario de la GN a pesar de condenar su uso discrecional. Esta contradicción

45 RODRÍGUEZ, Augusto, Reseña histórica del ejército argentino (1862-1930), Secretaría de Guerra, Dirección de Estudios Históricos, Buenos Aires, 1964, p. 38

46 Decreto, Buenos Aires, 14 de enero, 1862.

47 COMANDO EN JEFE DEL EJÉRCITO, Reseña histórica y orgánica del Ejército argentino, Círculo Militar, Buenos Aires, 1971, T. II, p. 77

48 Decreto, Buenos Aires, 18 de octubre, 1862.

49 Decreto, Buenos Aires, 31 de enero, 1863.

50 MACÍAS, Flavia, "Política, Guardia Nacional...", Op. Cit.

51 DE JONG, Ingrid, "Las alianzas políticas indígenas...", Op. Cit. 
representó quizás la herencia más problemática del sistema de la GN para el diseño institucional sobre el que se cimentaba el nuevo orden político. La participación de la GN en la frontera estipulada en las respectivas normativas de la Confederación y la provincia de Buenos Aires, continuó siendo motivo de debate hasta su licenciamiento a mediados de la década de 1870.

En calidad de nuevo presidente de la república, Bartolomé Mitre (1862-1868) abrió las sesiones parlamentarias de 1863 indicando las dificultades para sostener el EL de manera regular por la falta de una ley de conscripción que "obliga al Gobierno á llamar al servicio á Guardias Nacionales que sin disciplina, sin instrucción y sin el aplomo del soldado de línea, no se puede esperar de ellos más que un escaso é irregular servicio". ${ }^{52}$ Mitre vinculó así por primera vez la falta de un instrumento legal que garantizara el reclutamiento de un ejército permanente con la necesidad de recurrir a la GN, indicado la defensa de la frontera con "los bárbaros del desierto" como la principal urgencia. Pocos días antes, el nuevo gobernador bonaerense Mariano Saavedra, había reiterado a la asamblea provincial la promesa del gobierno nacional de hacer el servicio de frontera sólo con el EL debido a "los males e inconvenientes del actual sistema", esperando que los "habitantes de la campaña" obtengan "el descanso a que son ya acreedores". ${ }^{53}$ Como se verá esta promesa no se tradujo en la regulación jurídica hasta mediados de la siguiente década y el peso de las exigencias militares en este nuevo período continuó recayendo en los vecinos reclutados en la GN.

El 7 de agosto de 1863 se realizó el primer debate desde la creación del Congreso con relación al servicio de la GN en las fronteras, cuando Nicasio Oroño, diputado de Santa Fe, solicitó la presencia del ministro de Guerra, Juan Andrés Gelly y Obes. ${ }^{54}$ El ministro fundamentó el carácter auxiliar de la GN: el EL había abandonado las fronteras para repeler las montoneras que asolaban distintos puntos del Estado y para proveerse de soldados de línea el gobierno había recurrido a la GN, ya que ese era el sistema de defensa de Buenos Aires cuando se encontraba separada del resto de la república, al no contar con una ley de conscripción. Por su parte, el diputado porteño Pastor Obligado presentó un proyecto sobre movilización de la GN durante ofensivas indígenas mediante autorización parlamentaria. ${ }^{55}$ El mismo puede considerarse el primer instrumento parlamentario para evitar la discrecionalidad del PE sobre la GN y evitar su movilización indefinida (de acuerdo al sistema de defensa bonaerense aludido por Gelly) además de acercar posiciones de los representantes más críticos con la participación de la GN en la frontera. Gelly no se opuso al proyecto, y

52 InSTITUTO DE HISTORIA DEL PARLAMENTO ARGENTINO, El Poder Legislativo de la Nación Argentina, 1862-1868, Cámara de Diputados de la Nación, Buenos Aires, 1993, T. VII, p. 173

53 POGGI, Rinaldo, Los gobernadores de Buenos Aires..., Op. Cit., pp. 24-25.

54 InSTITUTO DE HISTORIA DEL PARLAMENTO ARGENTINO, El Poder Legislativo de la Nación Argentina, 1862-..., Op. Cit., pp. 352-354.

55 Ídem, pp. 355-357. 
aclaró que cuando el gobierno la movilizaba lo hacía por falta de tropas, amparado por la mentada ley porteña que indicaba que la GN "está llamada a hacer las veces de Ejército de Línea, en los casos ordinarios, como es el servicio de frontera". Los diputados porteños Emilio Castro y José Mármol insistieron en sus críticas sosteniendo que el uso de la GN en la frontera atacaba "la libertad del habitante de la campaña" y que éste "no tiene que pagar a la vez su dinero y contribuir con la sangre para formar el ejército". En cambio, los representantes políticos que abogaban por el recurso auxiliar de la GN aludían, en consonancia con Mitre, a la urgencia de la situación como causa de la excepcionalidad de la medida. "No hay otra manera de solucionarlo - afirmó Obligado - sino los indios llegarían hasta la Plaza de la Victoria". El proyecto no volvió a tratarse hasta 1864, cuando se autorizó al PE movilizar la GN de las provincias "cuyo territorio estuviese amenazado por los indios" para la defensa de sus fronteras. ${ }^{56}$

Durante la nueva etapa de reunificación institucional se agudizaron las contradicciones derivadas de la coexistencia del EL y la GN en el sistema de defensa estatal. Mitre insistió en recurrir a la GN "para cubrir los puntos de la frontera guarnecidos" ${ }^{57}$ y aumentar el EL con motivo de la guerra con Paraguay, preservando el papel destacado de la GN. Esto se manifestó en los proyectos del $\mathrm{PE}^{58}$ fundamentados en los argumentos que Mitre sostenía desde su asunción como presidente: la incapacidad para aumentar el EL debía ser suplida con la GN y con los infractores de las leyes vigentes, entre los que se incluía a los que no se enrolaban. Por uno u otro lado la presión del servicio de armas se procuraba efectiva. Mitre ordenó su movilización para la guerra ${ }^{59}$, la formación del ejército compuesto de diecinueve batallones de $\mathrm{GN}^{60}$ y sistematizó el enganche de personeros. ${ }^{61}$ Posteriormente las cámaras de representantes aprobaron un proyecto sobre enrolamiento presentado por

56 Ley 88, Buenos Aires, 11 de julio de 1864.

57 INSTITUTO DE HISTORIA DEL PARLAMENTO ARGENTINO, El Poder Legislativo de la Nación Argentina, 1862-..., Op. Cit., pp. 584

58 Ley 131, Buenos Aires, 5 de junio de 1865. Memoria presentada por el Ministro de Estado en el Departamento de Guerra y Marina al Congreso Nacional, Imprenta del Plata, Buenos Aires, 1868.

59 Decreto, Buenos Aires, 16 de abril de 1865.

60 Decreto, Buenos Aires, 17 de abril, 1865. Decreto, Buenos Aires, 23 de abril, 1865.

61 Buenos Aires, Decreto, 2 de mayo, 1865. Esta figura jurídica conformó un mercado con estructuras comerciales específicas de reemplazantes, en forma de avisos de pedidos y ofrecimientos que poblaron las páginas de la prensa mientras duró la convocatoria de la GN. Sobre quién recaía la función del personero es aún materia de estudio y puede ofrecer información sobre las estrategias para evadir la GN de acuerdo a los recursos económicos personales, del mismo modo que conocer las características económicas y sociales de aquellos en quien efectivamente recayó el servicio. Ver BARBUTO, Lorena y CORDERO, Guido, "Guardias Nacionales...”, Op. Cit. 
el PE como "ley de circunstancias y de situación sumamente apremiantes"62 que exceptuó a funcionarios públicos y reconoció "que la repetición de los enrolamientos perturba los trabajos de la campaña, ocasionando, entre otros males, la dispersión de los hombres y la interrupción de sus tareas". ${ }^{63}$ Por otro lado, el PE reconoció el carácter temporal del servicio en la frontera "que tienen que llenar por ahora los ciudadanos de la Campaña" e implementó algunas medidas para aliviar su servicio fronterizo, como por ejemplo que las licencias para trasladarse sean expedidas por los jueces de paz y no por los jefes de regimiento. ${ }^{64}$ Además en 1866 Adolfo Alsina, gobernador bonaerense, ordenó el cese en el cargo de juez de paz a comandantes de varios regimientos de GN (designados desde el PE nacional uno, provincial otro) por el peligro de que exista "una autoridad omnipresente" que abuse de "derechos y garantías individuales". ${ }^{65}$

El otro de los frentes que debió asumir el gobierno nacional y que agudizó las falencias del EL y reforzó la presión sobre la GN, fueron las rebeliones montoneras en las provincias. En el discurso normativo se adujo que el servicio de la GN en las fronteras derivaba de que el EL era destinado a combatir dichas rebeliones, sin embargo los decretos y leyes advierten que la movilización de la GN (siempre mediante autorización del Congreso) fue un recurso habitual también para sofocar las montoneras, aludiendo a la conservación del orden y el imperio de las leyes. En 1868 se movilizó la GN de la provincia de Corrientes; en 1869 la de Tucumán, Salta y Jujuy por los levantamientos de Felipe Varela y Ángel Peñaloza, y durante el receso parlamentario las cámaras autorizaron al PE intervenir en las provincias y "movilizar las milicias"; en 1870 se movilizó la de Buenos Aires, Entre Ríos, Santa Fe y Corrientes ante el levantamiento de Ricardo López Jordán; al igual que en 1873 y también en 1874 en ocasión de la rebelión dirigida por Mitre tras la elección presidencial de Nicolás Avellaneda ${ }^{66}$ De este modo, a pesar de que el argumento para la utilización de la GN en las fronteras fue la necesidad de concentrar los esfuerzos del EL en la guerra del Paraguay y los conflictos de la guerra civil, la GN tuvo un papel activo y destacado simultáneamente

62 Ley 129, Buenos Aires, 5 de junio de 1865. Instituto de Historia del Parlamento Argentino, El Poder Legislativo de la Nación Argentina, 1862-..., Op. Cit., p. 588.

63 Decreto, Buenos Aires, 7 de mayo, 1866.

64 Acuerdo, Buenos Aires, 20 de diciembre, 1866. También se exceptuó del servicio de frontera por diez años a los GN que finalizaran la guerra, se los premió con tierras en Chacabuco, se dispuso que las hijas de GN muertos pasen al Colegio de Huérfanas mantenido por el erario público y se subsidió a familias "menesterosas" de la GN.

65 COMANDO EN JEFE DEL EJÉRCITO, 1971, T. II, Op. Cit., p. 87.

66 Ley, Buenos Aires, 9 de octubre, 1868. Buenos Aires, Decreto, 5 de enero, 1869. Buenos Aires, Ley 321, 25 de agosto, 1869. Buenos Aires, Ley 391, 10 agosto, 1870. Buenos Aires, Ley 396, 16 de agosto, 1870. Buenos Aires, Ley 417, 24 de septiembre, 1870. Buenos Aires, Ley 588, 23 de mayo, 1873. Buenos Aires, Decreto, 31 de mayo, 1873. Buenos Aires, Ley 684, 24 de septiembre, 1874. 
en los tres frentes que debió atender el gobierno nacional para la construcción y consolidación del nuevo orden político. Por entonces, el departamento de Guerra constataba el predominio de las milicias en el servicio de armas: $3.392 \mathrm{GN}$ frente a 2.626 soldados del EL. En relación a la guerra con Paraguay, la memoria contó para el año 1867, 6.888 GN y 2.890 del EL. Según la mesa de revista de la Comisaría de Guerra de abril de 1866 a marzo de $1867,10.180$ soldados compusieron los batallones de GN, 6.561 su caballería y 1.650 los piquetes y contingentes, por sobre la caballería (2.696) y los batallones (3.978) del EL.

Las sugerencias del comandante en jefe de la frontera oeste de Buenos Aires, Nicolás Garmendia $^{67}$, al departamento de Guerra en 1867, cristalizaron los principales problemas del que se hacían eco los debates parlamentarios en materia de defensa y avance de la frontera: la perturbación del trabajo rural por la creciente presión de la GN sobre la población, la ineficacia de los relevos de los contingentes, su alto costo económico y la falta de disciplina. Desde el fortín de 9 de Julio afirmaba que el sistema vigente de contingentes semestrales de GN era ineficaz para proteger las fronteras, reiterando la necesidad de un ejército permanente, para evitar "el sacrificio de la Guardia Nacional" que precisamente por ser una milicia relevable jamás podría tomar una organización permanente y disciplinada, "sin contar las dificultades que ofrece la reunión de hombres que se hallan diseminados en distintos puntos y entregados á las faenas rurales". La solución era la pregonada por muchos parlamentarios en los últimos años y la prometida por Mitre en sus primeros días a cargo del gobierno nacional. Según Garmendia, por las aptitudes militares y el cariz profesional de un cuerpo militar permanente, bastaría con el apoyo de una cuarta parte de los GN que actualmente se requerían, destinados exclusivamente al cuidado de caballadas, ganado y trabajo en los fortines. A inicios de 1868, Alsina también intentó persuadir a Mitre para someter al Congreso la creación de regimientos de caballería, pero fue rechazado aduciendo que ni siquiera los regimientos previstos estaban completos. ${ }^{68}$

Los esfuerzos del sucesor de Mitre, Domingo Sarmiento (1868-1874), estuvieron dirigidos a terminar con la tradición miliciana provincial (de la que eran tributarias las montoneras) y limitar las prerrogativas militares de los gobernadores, que implicó revisar la coexistencia del EL y la GN. ${ }^{69}$ Para 1870 las relaciones entre el Estado y la sociedad indígena comenzaban a divergir, en tanto coexistían la confrontación armada y la consolidación de las relaciones basadas en acuerdos de paz, que trazaron un desigual grado de conflicto en las diferentes secciones de la frontera hasta la definitiva conquista de los territorios indígenas. ${ }^{70}$ Según Sarmiento todo el territorio que "se fue abandonando en diversos tiempos á las deprecaciones

67 Memoria presentada por el Ministro de Estado en el Departamento de Guerra y Marina al Congreso Naciona..., Op. Cit., anexo F, VIII-IX.

68 POGGI, Rinaldo, Los gobernadores de Buenos Aires..., Op. Cit., p. 32.

69 MACÍAS, Flavia, "Las fuerzas militares...", Op. Cit.

70 DE JONG, Ingrid, "Las alianzas políticas indígenas...”, Op. Cit. 
de los salvages [sic] ha sido en el pasado año devuelto y sometido al dominio y protección de nuestras leyes". ${ }^{71}$ En este logro incluyó el tratado con los caciques Limonao, Yanquetruz, Sayhueque y Calfucurá, entre otros que formaron parte del esfuerzo estatal por intervenir y ordenar las alianzas indígenas que resistían la expansión estatal, y que permiten analizar con mayor complejidad los dispositivos de poder involucrados en la frontera. ${ }^{72}$

En este contexto el nuevo departamento de Guerra insistió que la principal reforma pendiente en el sistema de defensa del Estado era la sustitución de la GN por el EL, y la próxima finalización del conflicto con el Paraguay se presentaba como una oportunidad idónea para hacerlo, ante la necesidad de "descargar á los moradores de la campaña de una contribución que ha llegado á inspirarles temor". ${ }^{73}$ Así lo hizo también cuando reglamentó la contribución de las provincias al EL, recomendando "un cambio radical en el sistema" porque la movilización de la GN ocasionaba altos gastos, era ineficiente por la falta de disciplina y porque debían acabarse "los abusos y violencias que trae consigo el envío de contingentes, dándole así a los habitantes de nuestra Campaña hogar que no tiene y garantías individuales de que desgraciadamente carece". ${ }^{74}$ Según el departamento de Guerra el avance de la frontera sobre los territorios indígenas de Pampa y Patagonia evidenciaba una y otra vez las limitaciones del EL y las estrategias de evasión de los sectores reclutados en la GN que debían auxiliarlo más por regla que por excepción..$^{75}$ A esto se añadía la dificultad de capturar a los desertores porque "rara vez pertenecen al partido de donde han sido enviados", siendo un pernicioso ejemplo para las tropas de línea con las "que viven en contacto diario". ${ }^{76}$ Esta falta de soldados explicaba el fracaso de los servicios de avanzada que debían recorrer diariamente la frontera, con un centenar de miembros de cuerpos de

71 InSTITUTO DE HISTORIA DEL PARLAMENTO ARGENTINO, El Poder Legislativo de la Nación Argentina, 1869-1874, Cámara de Diputados de la Nación, Buenos Aires, 1996, T. VIII, p. 161.

72 El tratado con Limonao incluía reconocerse súbdito argentino, la formación de una colonia agrícola militar y el servicio en la frontera como GN, lo que lleva a preguntarnos sobre un servicio militar similar o paralelo entre los "indios amigos". DE JONG, Ingrid, "Las alianzas políticas indígenas...", Op. Cit.

73 Memoria presentada por el Ministro de Estado en el Departamento de Guerra y Marina al Congreso Nacional, Imprenta Americana, Buenos Aires, 1870, XI.

74 Decreto, Buenos Aires, 28 de enero, 1870.

75 Memoria del Ministerio de Guerra y Marina, Imprenta de la Unión, Buenos Aires, 1872. En el informe se menciona: "De ahí la necesidad de ocurrir [sic] á los contingentes de GN con todos sus inconvenientes y gravámenes. La Guardia Nacional reclutada y remitida siempre violentamente, dá los peores resultados en el servicio, habiendose repetido los casos de decersión en masa con armas y caballos, abandonando los fortines cuya defensa les había sido encomendada".

76 Para paliarlo el departamento informaba que "los indios" de Catriel además del servicio ya encomendado, escoltaba a los GN de los fortines para evitar su deserción. 
caballería. Ninguno de los regimientos de la frontera había contado con la fuerza suficiente para el primer relevo de los destacados al frente de su línea, que junto a la falta de recursos para sufragar siquiera la mitad de los enganches, conducían a la necesidad de dictar una ley de reclutamiento "que salve al pais [sic]".

A inicios de la década de 1870 se observa en los debates parlamentarios de los sectores políticos dirigentes una creciente inquietud por el impacto del servicio de GN en la campaña bonaerense y su participación en la frontera con los territorios indígenas, además de reiterar su falta de efectividad. Más allá de los argumentos vertidos desde el PE a favor de la sustitución de la GN en la frontera, sea el departamento de Guerra o la presidencia del gobierno nacional, se continuó demandando a las cámaras de representantes autorizaciones para su movilización. Existió una clara contradicción entre lo dicho en las tribunas y los informes de gestión, y los proyectos de ley solicitados con carácter urgente, auxiliar y transitorio cuando no se hizo, como en muchos casos, mediante decretos y acuerdos ministeriales (durante y fuera del período legislativo); sin dejar de obviar además las observaciones y opiniones de las cámaras. Aquí pueden mencionarse dos ejemplos sobre la discrecionalidad del PE en relación al servicio de la GN en la frontera.

El primero es el proyecto de la Comisión Militar de diputados para autorizar al PE a movilizar la GN en las provincias que lindaban con el "desierto". ${ }^{77}$ En el debate de la cámara de diputados el representante de Santiago del Estero y miembro de la Comisión, apeló al argumento habitual: EL insuficiente y erario público incapaz de costear más enganchados. A pesar del rechazo del senado, finalizado el período legislativo el PE decretó la movilización de la GN bonaerense en la frontera de Santa Fe. ${ }^{78}$ El segundo ejemplo es el proyecto de la Comisión de Negocios Constitucionales, autorizando al PE movilizar la GN que considerase pertinente ante las deficiencias del EL en el servicio ordinario de fronteras ${ }^{79}$ Los diputados lo aprobaron en septiembre de 1871 rechazando todas las modificaciones propuestas por el senado ${ }^{80}$, autorizando movilizar el número de GN "que sea necesario" sin olvidar aclarar una vez más que el servicio era "meramente supletorio" y entre tanto no pueda ser desempeñado por el EL ${ }^{81}$ A raíz de esta discrecionalidad el vicepresidente Adolfo Alsina clausuró el período legislativo justificando dichas leyes nacidas "de una necesidad dolorosa" como era la defensa de la frontera e insistiendo en la creación de un ejército permanente que permita

77 INSTITUTO DE HISTORIA DEL PARLAMENTO ARGENTINO, El Poder Legislativo de la Nación Argentina, 1869..., Op. Cit., pp. 254-255.

78 Decreto, Buenos Aires, 26 de diciembre de 1871.

79 INSTITUTO DE HISTORIA DEL PARLAMENTO ARGENTINO, El Poder Legislativo de la Nación Argentina, 1869..., Op. Cit., pp. 392-394

80 Que el contingente fuera seleccionado al azar, igualar el sueldo al del EL y que la GN enviada a la frontera debía ser relevada cada año.

81 Ley 492, Buenos Aires, 10 de octubre, 1871. 
recurrir a la GN, "que es el pueblo armado", sólo en "grandes momentos y para los grandes peligros" y no para el servicio ordinario de fronteras. ${ }^{82}$

Las opiniones de Alsina encontraron continuidad en Sarmiento durante la apertura del ciclo parlamentario de 1872, donde la polémica participación de la GN en las fronteras ocupó importante espacio y en especial la necesidad de un nuevo marco normativo para establecer un ejército permanente. ${ }^{83}$ Sarmiento dedicó un inciso a explicar el orígen y la definición de la GN que incidía en su carácter auxiliar a partir del principio por el cual reposan en cada ciudadano el deber, la obligación y la necesidad de defender la propiedad, la vida y el honor nacional. Desde sus orígenes, afirmó, las poblaciones se armaron con el propósito de defenderse, hasta que una vez constituidas "en naciones" transformaron las defensas locales en un sistema común, que es la GN. Desde esta perspectiva, Sarmiento consideraba que el ejército regular sólo podía substituir a la GN cuando "esté en proporción" con las necesidades en materia de guerra. De otro modo, "la universalidad de ciudadanos constituye el ejército nacional" y si se rechazara este axioma o se limitara el "poder nacional militar sobre el uso de la GN, es suicidar la Nación". La carencia de un ejército nacional profesional y las prerrogativas provinciales sobre la GN eran para Sarmiento obstáculos en el proceso de construcción del nuevo orden político, haciendo "nacer por fuerza lo que con tantos sacrificios destruimos ó neutralizamos entre todos, á saber: las milicias" que lideradas por caudillos como Rosas, Quiroga, y Urquiza, habían conducido a la sublevación y la guerra civil. Aquí radicaban las razones que llevaron a Sarmiento a insistir en la sanción de una ley de reclutamiento militar; instrumento claro y sencillo "para que el Poder Ejecutivo ejerza en adelante el poder coercitivo de la Nación".

\section{De la ley de reclutamiento a la federalización de Buenos Aires (1872-1880)}

La década de 1870, y en especial la presidencia de Nicolás Avellaneda (1874-1880) significó la consolidación de un sistema político que garantizó la presencia del Estado nacional en las provincias a partir de instrumentos y mecanismos simultáneos implementados por los poderes locales y los representantes del poder central; nuevo actor que progresivamente ganó autonomía por encima de los escenarios provinciales. ${ }^{84}$ En este contexto la centralización del ejército nacional, o en palabras de Sarmiento el ejercicio del "poder coercitivo de la Nación" por parte del PE, implicó imponer una interpretación constitucional que subordinara

82 InSTITUTO DE HISTORIA DEL PARLAMENTO ARGENTINO, El Poder Legislativo de la Nación Argentina, 1869..., Op. Cit., pp. 401-402.

83 Ídem, pp. 419-420.

84 BRAGONI, Beatriz y MÍGUEZ, Eduardo (coordinadores) Un nuevo orden político..., Op. Cit., p. 27. 
a los gobernadores provinciales en materia militar ${ }^{85}$ y acabe con los intersicios normativos referentes a la organización y movilización de la GN. Hasta entonces, la unidad promulgada en 1853 no había dado paso a la centralización de la actividad y las estructuras políticas, que continuaban residiendo en las provincias. ${ }^{86}$

Sobre el final de la presidencia de Sarmiento se dictó finalmente la ley de reclutamiento del ejército, pero a pesar de considerarse el final del servicio de frontera de la GN, ésta conservó su rol auxiliar. ${ }^{87}$ La propia ley estipuló que contingentes de GN continuaran siendo una de las formas de reclutamiento (junto al alistamiento voluntario, enganches y destinados) suministrados por las provincias según su población censada y las plazas faltantes "para rellenar la totalidad del EL" elegidos por sorteo en cada localidad. Dos días después se autorizó al PE a movilizar la $10.000 \mathrm{GN}^{88}$ tras un extenso debate a partir de los encuentros del ministro de Guerra y la comisión de diputados encargada de dictaminar sobre proyectos de la frontera, que aludió a la equívoca estrategia gubernamental más concentrada en la aniquilación que en la "pacificación" ${ }^{89}$ Se estipuló que la GN forme "una línea interior de defensa con relación á la que actualmente ocupan las fuerzas", hasta que comience a aplicarse la ley de reclutamiento. ${ }^{90}$ Sarmiento recordaría a los legisladores que dicha ley "está aún por hacerse efectiva" y que no bastaba su consagración ni justeza de principios, sino su puesta en práctica, instando a los legisladores a no "lavar[se] las manos después de haber designado las cifras a que ha de llegar el ejército" ". "Aún así la Convención Constituyente de la provincia de Buenos Aires ordenó que hasta que "la Nación no provea [...] por sí sola" la fuerza para el servicio de las fronteras, éstas no serían más resguardadas por la GN sino por soldados alistados a expensas del Tesoro provincial. ${ }^{92}$

Esto confirmó una vez más la importancia de la GN en la frontera ya que promulgada la ley que estipulaba liberarla de dicho servicio, no se hizo efectivo hasta que el Estado garantizó la puesta en marcha de lo regulado, así como cerrar la etapa de mayores conflictos con la sociedad indígena. La situación de la frontera estaba cambiando en relación a las dos décadas anteriores a raíz de la resolución de las resistencias de los caudillos federales en las provincias y el fin de la guerra del Paraguay, que permitieron contar con mayores

85 MACÍAS, Flavia, "Las fuerzas militares...", Op. Cit.

86 SÁBATO, Hilda, "Resistir la imposición...", Op. Cit.

87 Ley 542, Buenos Aires, 28 de septiembre, 1872.

88 Ley 551, Buenos Aires, 30 de septiembre, 1872.

89 INSTITUTO DE HISTORIA DEL PARLAMENTO ARGENTINO, El Poder Legislativo de la Nación Argentina, 1869..., Op. Cit., pp. 506-515.

90 Ley 551, Buenos Aires, 30 de septiembre, 1872.

91 INSTITUTO DE HISTORIA DEL PARLAMENTO ARGENTINO, El Poder Legislativo de la Nación Argentina, 1869..., Op. Cit, pp. 757-758.

92 POGGI, Rinaldo, Los gobernadores de Buenos Aires..., Op. Cit., pp. 55-56 
recursos materiales para el avance de la frontera ${ }^{93}$; sin olvidar la muerte de Calfucurá en 1873 y los recientes tratados de paz con Catriel, Coliqueo y Raninqueo, "que gozan de las comodidades de la vida civilizada y de la protección del gobierno". En 1875, después de tres años de dictada la ley de reclutamiento, Avellaneda firmó el licenciamiento de la GN movilizada en las fronteras. ${ }^{94}$ Consideró que los regimientos y batallones disponían de las plazas suficientes y que no existían razones para temer que el orden público se altere, "único caso en que una necesidad imperiosa colocaría al Gobierno en el deber de apelar á la Guardia Nacional". De este modo, fue en los últimos años de existencia de territorios indígenas no sujetos al dominio estatal en Pampa y Patagonia, cuando jurídicamente se liberó a los vecinos de la campaña enrolados en la GN de cumplir servicio en la frontera. $\mathrm{Al}$ parecer, sólo la perspectiva de una pronta resolución del conflictivo avance fronterizo hacia el sur hizo a los sectores políticos dirigentes prescindir de la GN; sin las exigencias militares, además, que habían demandado la guerra en el Paraguay y el período más álgido de levantamientos provinciales.

Resuelta después de un cuarto de siglo la polémica de la frontera con el licenciamiento de la GN firmado por Avellaneda, el principal problema en la materia que afrontó el gobierno sobre el final del período de consolidación estatal fue la jurisdicción sobre su organización y movilización. Algunos años antes el Comisionado Nacional y Comandante en Jefe del Ejército del Interior, Wenceslao Paunero, había escrito al presidente Mitre en ocasión de las revueltas en Mendoza ${ }^{95}$, para informarle sobre la misiva recibida de Nicolás Villanueva, de aquel gobierno provincial, refiriéndose a la urgente necesidad de movilizar la GN. Villanueva solicitaba a Paunero autorización para hacerlo a cambio de informar sobre su organización. Paunero hizo extensiva la solicitud a Mitre y la repuesta fue lapidaria. El entonces presidente había respondido que no competía al gobierno nacional movilizar la GN y que era el gobierno provincial "en uso de sus propias facultades" el que podía hacerlo. Los sucesos de 1880 fueron el revés de esta trama. El gobierno nacional asumió una posición diametralmente diferente a la pregonada trece años antes por Mitre: será el comienzo del fin de la jurisdicción política provincial sobre la fuerza de la coerción y la prueba de que la centralización política y la consolidación estatal nacional era exitosa.

El punto de partida fue la decisión de Carlos Tejedor, gobernador de Buenos Aires, de reorganizar la GN, nombrar nuevos jefes y elevar las cuotas de hombres que debían aportar cada circunscripción ${ }^{96}$. Esto ocurrió al anunciar que no aceptaría la imposición de una

93 RATTO, Silvia, "El frustrado proyecto de avance territorial del Estado Nacional entre 1869-1872", Memoria Americana, 2011, 1 (19), pp. 93-119.

94 Ley, Buenos Aires, 14 de diciembre de 1875.

95 Memoria presentada por el Ministro de Estado..., Op. Cit., pp. 140-142

96 Decreto, Buenos Aires, 2 de septiembre de 1879 
candidatura gubernativa por parte del gobierno nacional. ${ }^{97}$ En vísperas del conflicto armado el presidente de la cámara provincial de senadores, José Moreno, envió al PE el proyecto de ley sancionado para la movilización de la GN de la provincia ${ }^{98}$, al tiempo que Tejedor la decretaba bajo el mando del coronel José Inocencio Arias. ${ }^{99}$

La respuesta del gobierno nacional no se hizo esperar. El mismo día que Tejedor emitió dichos decretos, desde el municipio de Belgrano el presidente Avellenda declaró rebeldes a los que obedecieran al gobernador porteño ${ }^{100}$, aludiendo al principio constitucional que establecía que era facultad del gobierno nacional "autorizar la reunión de las milicias [...] cuando lo exija la egecución [sic] de las leyes de la Nación y sea necesario contener las insurrecciones". Por tanto, estipuló que quien obedeciera la movilización dictada por el gobernador porteño cometía delito de rebelión y sería juzgado como tal, al tiempo que movilizó a las órdenes de las "Autoridades Nacionales" la GN de Buenos Aires, Entre Ríos, Santa Fé y Córdoba. Tejedor respondió decretando la ciudad de Buenos Aires en estado de asamblea, sujetó la GN y los voluntarios a la ley de milicias ${ }^{101}$, dio veinticuatro horas a los que aún no hubieran ocupado su puesto en las filas de la GN y días después ascendió a los jefes y oficiales de la GN que participaron de los combates "en Defensa de la Provincia de Buenos Aires". ${ }^{102}$

A través de leyes y decretos Avellaneda y Tejedor pujaron por investir al gobierno nacional o provincial de la soberanía jurisdiccional en relación a la movilización de la ciudadanía armada. La GN estuvo nuevamente en el centro de las disputas relativas a la construcción estatal y el legítimo uso de la fuerza pública de la coerción, que en el ámbito normativo se manifestó en las sucesivas regulaciones de uno y otro gobierno arrogándose prerrogativas militares y disponiendo sanciones. A un mes del pronunciamiento del gobernador porteño el gobierno nacional abatió la sedición. El 23 de junio se concertó el armisticio y renunció Tejedor, a lo que le siguieron las medidas del gobierno nacional para garantizar el control de la GN: prohibió el uso de uniforme militar a los individuos que no pertenecieran a la GN "movilizada en servicio de la Nación" autoridad provincial la formación y convocatoria de cuerpos militares "bajo cualquier denominación” 104 y reorganizó la GN “para levantar la institución de manera que responda

97 SÁBATO, Hilda, "Milicias, ciudadanía y revolución...”, Op. Cit., p. 228.

98 Ley provincial, Buenos Aires, 4 de junio de 1880,

99 Decreto, Buenos Aires, 5 de junio de 1880.

100 Decreto, Belgrano, 5 de junio de 1880.

101 Decreto, Buenos Aires, 22 de junio de1880.

102 Decreto, Buenos Aires, 30 de junio de 1880.

103 Decreto, Belgrano, 17 de julio de 1880.

104 Ley, Buenos Aires, 18 de octubre de 1880. 
á los fines de la Constitución Nacional" de acuerdo a "los disturbios causados por la última rebelión" 105 , al tiempo que federalizó la ciudad de Buenos Aires convirtiéndola en capital de la república. ${ }^{106}$

La revuelta de 1880 puso de manifiesto el vacío normativo sobre un problema recurrente en la GN, que fue el nudo de las tensiones entre los ámbitos locales de gobierno y el Estado, a saber qué instancia institucional tenía el poder de movilizarlas. A pesar de la injerencia que tenía el PE nacional sobre las unidades de la GN, sobre todo una vez que se encontraban movilizadas (igualando su condición al de EL), según lo establecido constitucionalmente eran las provincias las que debían nombrar los oficiales y regular su funcionamiento. El desenlace del conflicto constató el triunfo del gobierno nacional sobre la última provincia con arrestos de autonomía, vigorizando la organización e instituciones estatales después de tres décadas de luchas facciosas, al tiempo que surbordinó la GN garantizando el monopolio de la fuerza. ${ }^{107}$

\section{Conclusiones}

El análisis de la operacionalización normativa del funcionamiento de la GN así como el impacto jurídico de la situación fronteriza durante el proceso de construcción estatal entre 1852 y 1880 no puede prescindir del marco más general en el que se inscribió la institución, y que es la configuración de la fuerza pública de la coerción. Precisamente uno de los desafíos en esta etapa fue la falta de un ejército permanente profesional y las crecientes exigencias militares derivadas de la defensa y avance de las fronteras con los territorios indígenas de Pampa y Patagonia, junto a los conflictos intra e interprovinciales y la guerra del Paraguay. Esto derivó en la articulación del EL y la GN en el sistema militar, y generó una ambigüedad que en el caso de la GN conllevó, entre otros hechos, a la polémica sobre la jurisdiccionalidad de su movilización y su participación auxiliar en la frontera. Sin embargo, el nuevo orden político requería la subordinación de poderes en competencia y esto sólo pudo completarse con éxito en 1880. Después de Pavón se "nacionalizó" el ministerio porteño de Guerra y se procuró homogeneizar en términos estatales la normativa de la GN, pero continuó correspondiendo a las provincias su organización. Desde finales de la década de 1860 el gobierno nacional procuró limitar las prerrogativas militares provinciales pero no fue hasta el triunfo sobre la última provincia con arrestos de autonomía, Buenos Aires, que se clausuró la dualidad jurisdiccional sobre la GN, garantizando el monopolio de la

105 Decreto, Buenos Aires, 10 de diciembre de 1880. Memoria del Ministerio de Guerra y Marina presentada al Honorable Congreso por el Ministro de Guerra y Marina Dr. Benjamín Victorica, Establecimiento Tipográfico de La Pampa, Buenos Aires, 1881, T. I.

106 Ley 1029, Buenos Aires, 20 de septiembre de 1880.

107 SÁBATO, Hilda, “Milicias, ciudadanía y revolución...”, Op. Cit., p. 228-229. 
fuerza, o en palabras de Sarmiento, "que el Poder Ejecutivo ejerza en adelante el poder coercitivo de la Nación".

En el caso de la GN bonaerense, la copiosa regulación destinada a fijar su organización y funcionamiento constata el protagonismo que adquirió en el proceso de formación y consolidación estatal. Las leyes y decretos promulgados para organizar (y optimizar) el enrolamiento de los ciudadanos y determinar su participación en las fronteras, fueron avalados por la falta de un ejército permanente y la escasez de hombres para la fuerza de la coerión. Las primeras normas dictadas, por un lado castigaron con el servicio en el EL la evasión de una obligación considerada constitutiva del estatus ciudadano (el enrolamiento) y por otro fijaron su función auxiliar en la frontera. Buenos Aires fue la primera provincia que instituyó la GN (a escasas semanas de derrocado Rosas) y las medidas adoptadas para su organización tendieron a controlar la población domiciliada mediante documentos emitidos por las autoridades locales de la campaña y la autorización militar para aprehender y destinar al EL a los no enrolados. La consideración del papel del individuo en la estructura económica de la campaña fue recurrente y sugiere una importante resistencia social a participar en la GN, agudizada por la discrecionalidad relativa al servicio en la frontera. Las normas se elaboraron muchas veces en virtud de los trabajos en la campaña, estipulando excepciones según ocupación laboral y en algunos casos, considerando los ciclos productivos para la organización de los contingentes. El trabajo fue una cuestión relevante, reflejando la preocupación por minorar el impacto de la GN en la economía de la campaña, quizás por la presión de sectores terratenientes preocupados por las crecientes demandas militares del Estado en un contexto de escasez de mano de obra.

El auxilio de la GN en la frontera fue otro motivo de extensos debates y disputas en los sectores políticos dirigentes desde la década de 1850 hasta su licenciamiento en 1875 , cuando se puso en marcha la ley de reclutamiento del ejército. Los problemas derivados del avance de las fronteras sobre los territorios indígenas más los conflictos facciosos y la guerra del Paraguay, agudizaron las carencias de efectivos para el ejercicio de la coacción. Esto fue la base para que el discurso normativo reforzara el carácter auxiliar necesario e ineludible de la $\mathrm{GN}$ a pesar de condenar en ocasiones su uso discrecional. Existió una constante contradicción entre lo dicho en las tribunas y los informes de gestión, y los proyectos de ley solicitados por el PE con carácter urgente y transitorio; entre los argumentos que excusaban las decisiones normativas y las prácticas inmanentes del sistema de fronteras. A pesar de que la utilización de la GN en las fronteras fue explicada por la necesidad de concentrar los esfuerzos del EL en la guerra del Paraguay y/o los conflictos de la guerra civil, la GN tuvo un papel activo y destacado simultáneamente en los tres frentes que debió atender el gobierno nacional. El peso de las exigencias militares derivadas de la creación del nuevo orden político recayó en la población en cumplimiento de la obligación ciudadana del servicio de armas. Fue sólo en los últimos años de existencia de territorios indígenas no sujetos al dominio estatal en Pampa y Patagonia, cuando jurídicamente se liberó a los vecinos de la campaña enrolados en la GN de cumplir servicio en la frontera. Al parecer, fue la perspectiva de una pronta 
Avances del CESOR - Año IX, $N^{\circ} 9 / 2012$

resolución del conflictivo avance estatal hacia el sur lo que llevó a los sectores políticos dirigentes a prescindir del servicio de armas de los vecinos de la campaña bonaerense; en palabras de Garmendia, poner fin a "el sacrificio de la Guardia Nacional".

Recibido: 22/11/2011

Aceptado: 19/03/2012 